\title{
Volunteer patients and small groups contribute to abdominal examination's success
}

\author{
Helen M Shields' \\ Nielsen Q \\ Fernandez-Becker ${ }^{2}$ \\ Sarah N Flier ${ }^{2}$ \\ Byron PVaughn ${ }^{2}$ \\ Melissa H Tukey ${ }^{2}$ \\ Stephen R Pelletier ${ }^{3}$ \\ Douglas A Horst ${ }^{2}$ \\ 'Department of Medicine, Brigham \\ and Women's Hospital and Harvard \\ Medical School, Boston, MA, \\ ${ }^{2}$ Department of Medicine, Beth \\ Israel Deaconess Medical Center \\ and Harvard Medical School, Boston \\ MA, ${ }^{3}$ Center for Evaluation, Harvard \\ Medical School, Boston, MA, USA
}

Correspondence: Helen M Shields Department of Medicine, Brigham and Women's Hospital, 75 Francis Street, Boston, MA, 02115, USA

$\mathrm{Tel}+\mathrm{I} 6175259315$

Fax +l 6175258740

Email hmshields@bwh.harvard.edu

\author{
This article was published in the following Dove Press journal: \\ Advances in Medical Education and Practice \\ I November 2017 \\ Number of times this article has been viewed
}

Background: Prior to 2007, we taught the abdominal examination in a hospital based group to 40 students, at one hospital. We used volunteer patients, small groups, repetition, and required faculty development sessions. In 2007, our medical school changed its "Introduction to Physical Examination" session so that the entire class was to be taught in a geographically central session. Our hospital was selected to lead the abdominal examination portion of the session.

Aim: Our aim was to answer three questions. First, could we quadruple the recruitment of volunteer patients, and faculty? Second, was it volunteer patients, small groups, repetition, or faculty training that was most valued by the students? Third, would volunteer patients and/or faculty agree to participate a second time?

Methods: A total of 43-46 patients and 43-46 faculty were recruited and 43-46 examining rooms were obtained for each of the 5 years of this study. Teachers were required to attend a 1-hour faculty development session. The class of about 170 students was divided into 43-46 groups each year. The teacher demonstrated the abdominal examination and each student practiced the examination on another student. Each student then repeated the full abdominal examination on a volunteer patient. Results: Over the 5-year time period (2008-2012), the abdominal examination ranked first among all organ systems " Introductory Sessions". The abdominal examination ratings had the best mean score (1.35) on a Likert scale where 1 is excellent and 5 is poor. The students gave the most positive spontaneous comments to having volunteer patients, with small groups coming in as the second most appreciated educational element.

Conclusion: We successfully quadrupled the number of faculty, patients, and examining rooms and created a highly rated educational program as measured by anonymous student evaluations, patient and faculty participation, and the medical school's selecting the abdominal examination methods as an "Advanced Examination" for the Pathways Curriculum.

Keywords: abdominal examination, volunteer patients, small groups, repetition, faculty development

\section{Background}

Residency directors and others have noted significant variability in the physical examination skills of medical students, residents, and attending physicians..$^{1-8}$ Controversy exists, however, about the basic questions of when and how students should learn their physical examination skills. ${ }^{9}$ Should they be taught before, during, or after their clerkships? ${ }^{9}$ In addition, the best methods for teaching the abdominal examination have been explored and debated. ${ }^{10,11}$ Should real patients ${ }^{10-13}$ or standardized patients be used ${ }^{14-16}$ Should lay patient teachers ${ }^{17}$ or dummies ${ }^{18}$ be included as effective teaching tools? Should intensive extra sessions be given? ${ }^{19}$ What is the optimum number of students to teach in a group $?^{11}$ 
The abdominal examination has been singled out as particularly challenging to teach to medical students. ${ }^{20}$ In 2007 , our medical school changed its "Introduction to the Physical Examination" for each organ system to a single introductory afternoon session from 1:30-5:30 PM for a second-year class of approximately 170 second-year medical and dental students combined. Previously, each teaching hospital associated with the medical school held the introductory session with different formats at individual hospitals. Each major hospital had had approximately 40 students to teach. At one hospital, Beth Israel Deaconess Medical Center, the co-course directors (Dr Helen Shields [HS] and Dr Douglas Horst [DH]) had used small groups with 3-5 students with one teacher and one volunteer patient per group. When these two course directors were selected to direct the entire class's abdominal examination in a central session in 2007 , we were faced with the major educational challenges of how to effectively teach a large class of students the abdominal examination in a short time period while continuing to use small groups and volunteer out-patients.

This paper details the key methods and strategies we used to teach the centralized session abdominal examination from 2008-2012 to approximately 170 second-year medical students in the same manner as we had 40 students the prior year at one hospital using almost four times the number of volunteer patients, trained faculty, and small groups, and describes students' responses to the new curriculum.

We had the following three questions we wished to study: First, could we translate an exercise that was rated highly by 40 students into one highly rated by 170 students? Second, what was most important to the students - the volunteer patients, small groups, repetition, or faculty? Third, would patients or faculty members teach with us more than once?

\section{Methods}

We chose a format with an auditorium demonstration of the physical examination of the abdomen on a volunteer patient. This was followed by the class breaking up into 43-46 small groups, depending on the year, with one teacher to 3-5 students for a hands-on practice session at the medical school's examining rooms or an adjacent hospital's clinical outpatient examining rooms. The hands-on practice session had two components. First, students practiced on each other in single sex groups. Second, students repeated practice of the examination by having each student examine a volunteer "mystery" patient's abdomen under the supervision of the teaching physician and the observing eyes of the other students. To recruit patients from a general gastroenterology clinical practice, HS and $\mathrm{DH}$ asked each patient she/he saw in clinic if he/she was interested in being examined by medical and dental students and providing a bit of medical history. Depending on the year and class size, we recruited 43-46 outpatients and 43-46 adult and pediatric gastrointestinal (GI) faculty, internal medicine faculty, gastroenterology fellows, surgeons or internal medicine residents to teach the 2-hour abdominal examination. Each teaching faculty member attended a 1-hour faculty development session the week before or had an individual tutorial with one of the course directors (HS).

\section{Data collection and analysis}

From 2008-2012, second-year medical and dental students used Harvard Medical School's MyCourses CourseEvaluation Web Site to submit their required responses to the Likert-type questionnaire that asked questions about the faculty member's effectiveness and contribution to their learning. In addition, an open-ended question was asked about comments on the positives and negatives of the session. The total number of students in each of the 5 years of classes who were asked to fill in anonymous online evaluations is as follows: 174 students (2008); 175 students (2009); 166 students (2010); 168 students (2011), and 174 students (2012).

The specific MyCourses questions asked the student to first rate the central session lectures by $\mathrm{HS}$ and $\mathrm{DH}$ on a Likert scale where 1 is excellent and 5 is poor. The next set of questions asked the student on the same Likert scale to rate the small group examination component of the session, give the name of the small group preceptor, rate the small group preceptor, rate the handouts, rate the audiovisual aids, rate the session overall, list the strengths of this session, and list the things you would change for next year's session.

From the list of "strengths" of the session, four themes of excellence were identified by the students as things they appreciated in the learning session. These were as follows: 1) volunteer patients, 2) small groups, 3) repetition, 4) faculty. The spontaneous comments about each of these themes were pulled out from each year's evaluations.

\section{Statistical analyses}

Ranking was used to determine the order of the overall score for each of the ten central different organ specific physical examination sessions. A Z-test of proportions was used for comparison of the rank and specialty of faculty involved in each of the 5 years. Statistical significance was set at the confidence level of 0.05. Harvard Medical School Institutional Review Board approval was obtained in September 2007 for study and analysis of the anonymous online student evaluations of the physical examination sessions from 2008-2012. 
The abdominal examination exercise began in the medical school auditorium with a 10 -minute discussion of the etiology of abdominal pain, followed by a 20-minute discussion of the classic characteristics of abdominal pain due to appendicitis. The patient with appendicitis had classic computed tomography findings that were reviewed.

1. A volunteer outpatient is examined by course director (DH) to demonstrate specific hands-on techniques for each of the four parts of the exam, inspection, auscultation, percussion, and palpation. A Power Point slide presentation was projected on a screen behind the course director to provide visual reinforcement of the teaching points and magnified illustrations of the maneuvers being demonstrated.

2. Afterward, the class of 170 students was divided into 43-46 groups with approximately four students in each group, one teacher, and one volunteer "mystery" patient. Each group had 2 hours for demonstration and practice. The small group session started with the teacher demonstrating the abdominal examination on a student who volunteered to be examined, and then each student in turn, practiced the examination on another student in front of the group to get immediate feedback on technique.

3. In the final 45-60 minutes, the teacher then asked each student to independently perform the examination on the volunteer "mystery" patient who was waiting outside the examining room. No information is given to the students about the patient's history before the examination of the abdomen so that the students can try to reason out the patient's problem from the findings on the examination. When these examinations are finished, the session concluded with the volunteer patient having a 5-10 minute opportunity to share information about his/her medical history and give feedback to the students about their performance.

4. Students were required to complete the same anonymous standardized online evaluation from the medical school for each organ system. The other organ systems that the students evaluated for teaching the physical examination in alphabetical order were: cardiovascular, dermatology, eye examination, genitourinary and gynecologic examinations, head and neck, musculoskeletal: low back, musculoskeletal: shoulder and hand, musculoskeletal: knee and lower leg, pediatric examination, and pulmonary examination.

\section{Behind the scenes arrangements to ensure the abdominal examination exercise runs smoothly}

1. Six months before the session, "save the date" letters were sent to outpatients and email messages were sent to physicians.
2. The hospital hosting the exercise blocked clinic rooms for teaching on the day of the exam.

3. Patients were recruited months in advance in person, in clinic, or by phone by HS or DH, they are provided free parking, at a cost of US\$500.00 for all 46 patients, and a medical school certificate of appreciation.

4. Teachers were required to attend a 1-hour evening faculty development session where one of the course directors (HS or DH) demonstrates the proper sequence of the examination on a different volunteer patient, each of three separate nights during the week preceding the exercise. Teachers who could not attend an evening session received an individual tutorial (HS). Each teacher was given an extensive packet of reading materials about how to do the examination correctly so that each teacher was prepared to teach effectively. ${ }^{21-26}$

5. Just prior to the teaching session, each volunteer patient was called by the small group teacher to introduce him or herself, review the current history and physical findings of the "mystery" patient provided.

6. On the day of the exam, each volunteer "mystery" patient was escorted to the examining room by a fourth-year medical student. Each fourth-year medical student was given a gift certificate for US\$50.00 for his/her help (US\$300.00) over the 2.5-hour period.

\section{Differences in method of abdominal examination teaching compared to the other central sessions}

1. Only one other organ system had 16 real patients for the students to examine at the medical school. This session had the second best ranking for physical examination teaching compared to the abdominal examination. It used patients to demonstrate key physical findings. Students examined patients in rotating small groups during this organ system session.

2. One other organ system brought in one patient for an auditorium demonstration by the course director of the method for examination.

3. The other organ systems relied on the students examining each other in small or large groups, with a teacher, after listening in the auditorium, to how to examine the patient.

\section{Results}

Over the 5 academic years 2008-2012, the abdominal examination session ranked first in required anonymous student evaluations, among all the organ systems' physical examination sessions at our medical school. The abdominal examination 
ratings had the lowest mean score (1.35) (Table 1) on a Likert scale where 1 is excellent and 5 is poor. The abdominal examination also had the smallest standard deviation compared to any other organ system's physical examination at our medical school (0.560) (Table 1). The abdominal examination's evaluations were unique in that no evaluation from any of the 400 students over the 5-year period fell below an average rating (rating of 3). All other physical examinations had their lowest ratings in the fair (rating of 4 for one organ system course), or poor (rating of 5 for eight other organ system courses) categories. From 2008-2012, the other organ systems that the students were evaluating for the teaching of the physical examination in alphabetical order were: cardiovascular, dermatology, eye examination, genitourinary and gynecologic examinations, head and neck, musculoskeletal: low back, musculoskeletal: shoulder and hand, musculoskeletal: knee and lower leg, pediatric examination, and the pulmonary examination.

The next best session after the abdominal examination, Session 1 in Table 1, used 16 volunteer patients to illustrate specific disease states. Students examined these patients in groups with a preceptor at the medical school rather than in a hospital setting.
In 2015, our medical school made major changes in the curriculum, shifting to a 14-month long first year followed by the principal clinical year, a flipped classroom model for students' learning in the first year was chosen. All central sessions for physical examination are scheduled earlier in the pre-clinical curriculum. Only two courses were chosen to be "advanced central sessions" in the New Pathways Curriculum, the abdominal examination and the second ranked specialty organ system that also used live patients to demonstrate physical findings to the students.

A variety of different types of physicians at different academic ranks taught the abdominal examination over the 5 -year period as shown in Table 2. Both "attendings" in adult and pediatric gastroenterology and Gastroenterology fellows in adult and pediatric gastroenterology were well represented. Surgeons, medical residents, hospitalists, a fourth-year medical student and a pathologist also taught over the 5 years. No rank or specialty was significantly associated with a better evaluation score.

The sex of the teachers changed over the 5-year period with more women as teachers in 2011-2012. However, no statistically significant difference was noted in the years when more

Table I Ranking of second-year introductory organ system physical examination sessions by anonymous student evaluations

\begin{tabular}{llllll}
\hline & N & Highest rating & Lowest rating & Mean & Standard deviation \\
\hline Abdominal examination & 400 & $\mathrm{I}$ & 3 & 1.35 & 0.560 \\
Session I* & 406 & $\mathrm{I}$ & 5 & 1.37 & 0.634 \\
Session 2** & 893 & $\mathrm{I}$ & 5 & $1.5 \mathrm{I}$ & 0.713 \\
Session 3 & 472 & $\mathrm{I}$ & 5 & 1.57 & 0.728 \\
Session 4 & 439 & $\mathrm{I}$ & 5 & 1.61 & 0.716 \\
Session 5 & 255 & $\mathrm{I}$ & 4 & 1.67 & 0.774 \\
Session 6 & 256 & $\mathrm{I}$ & 5 & 1.68 & 0.853 \\
Session 7 & 294 & $\mathrm{I}$ & 5 & 1.93 & 0.885 \\
Session 8** & 728 & $\mathrm{I}$ & 5 & 1.93 & 0.849 \\
Session 9 & 322 & $\mathrm{I}$ & 5 & 1.94 & 1.024 \\
\hline
\end{tabular}

Notes: "Please rate the session overall (I= Excellent 2=Very Good, 3=Average, 4=Fair 5= Poor)". *Session I through 9 lists student evaluations for other organ system's introductory physical examination sessions (pulmonary, cardiovascular, etc.). ${ }^{* * T}$ Two sessions in the same topic area combined.

Table 2 Rank and specialty of abdominal examination teachers (2008-2012)

\begin{tabular}{|c|c|c|c|c|c|}
\hline & $\begin{array}{l}2008 \\
(n=46)\end{array}$ & $\begin{array}{l}2009 \\
(n=44)\end{array}$ & $\begin{array}{l}2010 \\
(n=44)\end{array}$ & $\begin{array}{l}2011 \\
(n=45)\end{array}$ & $\begin{array}{l}2012 \\
(n=45)\end{array}$ \\
\hline $\mathrm{Gl}$ attending & $43 \%(20)$ & $39 \%(17)$ & $48 \%(21)$ & $47 \%(2 I)$ & $44 \%(20)$ \\
\hline GI fellow & $26 \%(12)$ & $25 \%(11)$ & $27 \%(12)$ & $22 \%(10)$ & $22 \%(10)$ \\
\hline Pediatric $\mathrm{Gl}$ attending & $7 \%(3)$ & $9 \%(4)$ & II\% (5) & II\% (5) & $13 \%(6)$ \\
\hline Pediatric GI fellow & $4 \%(2)$ & $9 \%(4)$ & 0 & $4 \%(2)$ & $2 \%(I)$ \\
\hline Surgeon & $15 \%(7)$ & $14 \%(6)$ & $9 \%(4)$ & $2 \%(I)$ & $2 \%(1)$ \\
\hline Pathologist & 0 & 0 & 0 & $2 \%(I)$ & 0 \\
\hline Hospitalist & $2 \%(I)$ & $2 \%(I)$ & $2 \%(I)$ & $7 \%(3)$ & $7 \%(3)$ \\
\hline Resident in medicine & $2 \%(1)$ & $2 \%(I)$ & $2 \%(1)$ & $2 \%(I)$ & $7 \%(3)$ \\
\hline Fourth-year medical student & 0 & 0 & 0 & $2 \%(I)$ & $2 \%(1)$ \\
\hline
\end{tabular}

Abbreviation: Gl, gastroenterology. 
women physicians taught compared to fewer women teachers. Students were divided up into single sex groups of men or women students during this 5-year period at the medical school. Teachers were not specifically paired with students based on sex so that a man teacher could have a women's student group and a woman teacher have a men's student group.

Doctors enjoyed teaching the abdominal examination as evidenced by Figure 1. Out of 106 doctors who participated over the 5 years, 43 doctors participated twice and 28 doctors participated from three to five times (26\%). Doctors were paid a standard hourly medical school rate of US $\$ 100.00$ for their face time with the students. Abdominal examination teaching was considered 2 hours of direct face time.

Patients enjoyed being part of the abdominal examination as shown in Figure 2. The majority of patients volunteered more than one time with 33 out of a total of 84 patients volunteering three, four or five times $(39 \%$ for three, four or five times combined) over the 5-year period.
The total monetary cost for the abdominal examination per year was US\$800.00 for approximately 170 students. We paid approximately US\$500.00 for patient parking costs to the 43-46 patients each year and US\$300.00 for the six fourth-year student helpers' gift certificates.

While all central sessions had recommended faculty development prior to teaching, the abdominal examination required teachers who wished to teach to attend one of the three evening faculty development sessions the week before, or have a private tutorial with one of the course directors (HS) in person or over the phone.

Table 3 shows the "abdominal examination strengths" comments for the 5-year period placed into four major categories that were established after reading each of the "strengths" listed by the students over the 5-year period. All strengths were in the anonymous online student evaluations on MyCourses under the medical school heading of abdominal examination. The four types of categories of

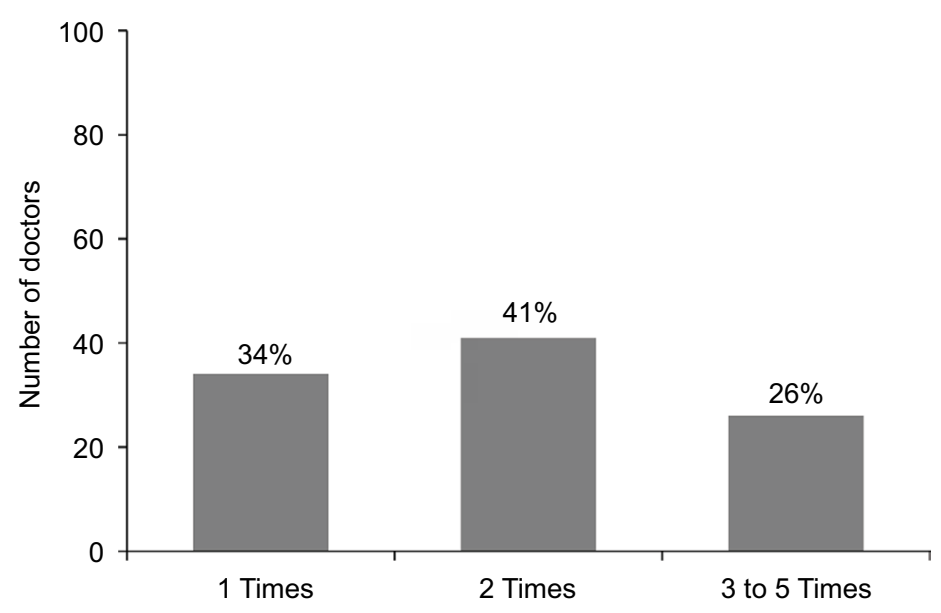

Figure I Number of doctors who taught one or more times over the 5-year period from 2008 to 2012 .

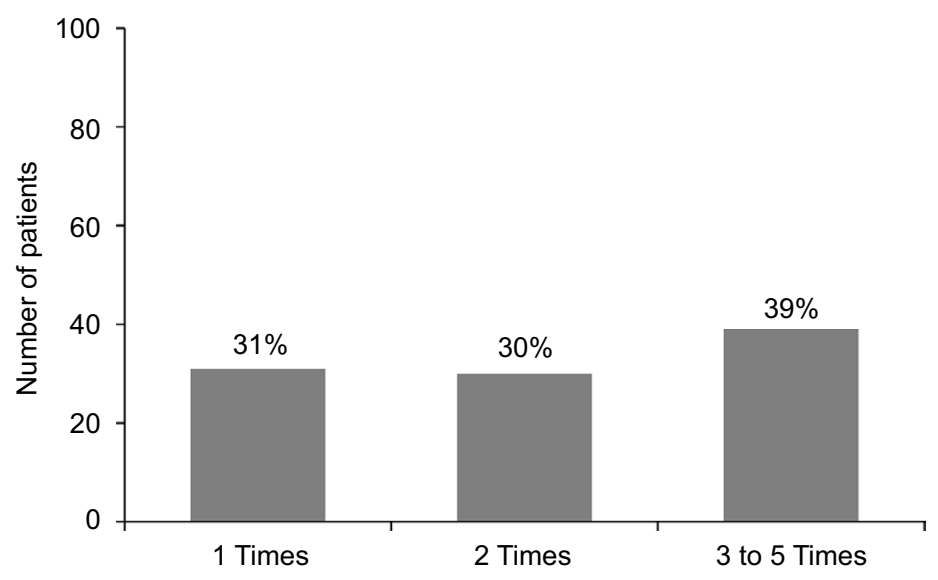

Figure 2 Number of patients who volunteered one or more times over the 5-year period from 2008 to 2012 . 
Table 3 Spontaneous student comments about abdominal examination session, coded* (2008-20I2)

\begin{tabular}{|c|c|c|c|c|c|}
\hline & $\begin{array}{l}2008 \\
(n=89)\end{array}$ & $\begin{array}{l}2009 \\
(n=63)\end{array}$ & $\begin{array}{l}2010 \\
(n=120)\end{array}$ & $\begin{array}{l}2011 \\
(n=58)\end{array}$ & $\begin{array}{l}2012 \\
(n=105)\end{array}$ \\
\hline Liked real patients & $43 \%(38)$ & $43 \%(27)$ & $40 \%(48)$ & $38 \%(22)$ & $30 \%(32)$ \\
\hline Liked small groups & $36 \%(32)$ & $38 \%(24)$ & $33 \%(40)$ & $22 \%(13)$ & $35 \%(37)$ \\
\hline Liked teachers & $16 \%(14)$ & $24 \%(15)$ & $14 \%(17)$ & $17 \%(10)$ & $20 \%(2 I)$ \\
\hline Liked repetition & $13 \%(12)$ & $14 \%(9)$ & $25 \%(30)$ & $19 \%(11)$ & $30 \%(32)$ \\
\hline
\end{tabular}

Note: *Percentages reported total more than $100 \%$ due to multiple responses from students.

strengths were decided after reading all spontaneous comments. These strengths are: 1) real patients, 2) small groups, 3) repetition (practice) during the session, and 4) teachers. The data show that the most common positive comment is "liked real patients", but "liked small groups" (is the second most common strength with "liked repetition" third and "liked teachers" fourth as a spontaneous comment.

\section{Discussion}

We present a template for teaching the abdominal examination effectively, efficiently, and well over a 5-year period. We have identified four factors that contributed most to our top ranking. We chose these four factors after reviewing all spontaneous free text comments from the students over the 5 years that were mentioned as "strengths" in the online evaluation forms. The most important factor from our students' point of view is having volunteer patients. The second is small group size. Third, is the additional practice opportunity that having the volunteer patient provided. The fourth factor is the teacher's enthusiasm, kindness, knowledge, and patience in teaching the abdominal exam.

The organ system examination that was closest to the abdominal examination (Session 1) also used real patients to demonstrate findings. This fact again supports the importance to students of having real patients demonstrating real findings for learning the physical examination. ${ }^{10,11}$

Currently the medical school has chosen the abdominal exam, and the specialty examination ranked second from 2008-2012 to be the only "advanced physical examination sessions" at the medical school centrally for all students in the Pathways Curriculum. Both sessions, as noted previously, use real volunteer patients. We were delighted to be chosen and rolled out our first and second advanced abdominal examination sessions on April 20, 2016 and April 19, 2017.

Support for practice on real patients comes from the literature on teaching physical examination skills. ${ }^{10} \mathrm{~A}$ survey to all course directors for physical examination at both allopathic and osteopathic medical schools in 2001 was completed by 83 course directors (allopathic $=76$ and osteopathic $=16$ ).${ }^{10}$ While the course directors who completed the survey noted that practice on peers was the most common method used with the second most common method being practice on patients or live human models, the course directors also noted that the best method for teaching the physical exam, in their view, was to use real patients..$^{10}$ Greater than $50 \%$ of the course directors recommended demonstrating the examination initially on a standardized patient and then having the students practice on a real patient. ${ }^{10}$ The perceived obstacles in this survey to using real patients, real or standardized, were time, money, and logistics. ${ }^{10}$ For our abdominal examination, we send out "save the date" letters 6 months ahead of the medical school's physical examination date to each clinic patient of HS or DH who has agreed in the clinic or over the phone (HS or DH) to teach in the examination. Having the same administrator, Francisca Xavier-Depina, for the 5-year period who was well known to the clinic patients, helped facilitate recruitment. The total cost of our yearly session was less than US $\$ 1,000$ for patient parking and gift cards for the fourth-year tutors who acted as guides over the 2-hour period so that each of the patients arrived at the appropriate clinic lobby and/or examination room for their group. This expense was paid out of a discretionary fund (HS) from grateful patient funds. The other cost of using hospital clinic rooms from 3:30-5:30 PM on a weekday was borne by the academic teaching hospital.

According to their personal reports, the patients enjoyed coming in to meet the students and the teaching physician. A significant number of the 84 patients (39\%) were repeat volunteers for three, four or five times between the years 2008-2012.

Two methods for teaching the abdominal examination have recently been introduced as pilot projects. Lay teaching associates who use their bodies as a method of teaching the examination were compared in a pilot study to physician teachers. ${ }^{17} \mathrm{Of}$ interest, the students taught by the lay associate teachers had a higher objective structured clinical examination (OSCE) score on the abdominal examination compared to the students taught by the physician teachers. ${ }^{17}$ Physician educators in Singapore developed the NUS (National University of Singapore) Tummy Dummy (NUS-TD) as a portable, inexpensive abdominal 
simulator that received a positive response from a pilot group of 44 students. ${ }^{18}$

We used a ratio of one teacher to four students the overwhelming majority of time. Rarely a group had three or five students. Smith et al used a ratio of one teacher to four students with weekly organ-based teaching sessions at the bedside of hospitalized patients. ${ }^{11}$ Of interest, the abdominal examination score significantly improved $(p=0.0004)$ on the subsequent OSCE. ${ }^{11}$ Junger et al used groups of five students at the bedside for teaching physical examination skills in both his experimental additional teaching session and control groups. ${ }^{13}$

Doctors taught more than once in the majority of cases. Slightly more than a quarter of the 106 teachers (26\%) taught between three to five times over the 5-year period of 2008-2012 with 13\% teaching three times, 7\%, four times, and $6 \%$, five times.

Chang and Power have reviewed students' comfort with examining each other as part of a physical examination course. ${ }^{27}$ Chang and Power's questionnaire results suggested that students were in fact comfortable with examining each other except in sensitive physical areas such as breasts, rectum, and genital exams. ${ }^{27}$ Single sex groups were used during the 5 years from 2008-2012 of our abdominal examination study. However, for the advanced abdominal examination in 2016 and 2017, students chose ahead of time whether they wished to be in a single sex or mixed sex group for each teaching session.

Practice and repetition of the structured examination using the identical order of inspection, auscultation, percussion followed by palpation was repeatedly cited as one of the best things about the session. Stillman et $\mathrm{al}^{28}$ queried two different medical schools about their teaching methods. One school used a highly structured method such as ours, while the other school used a less structured approach. Students were videotaped and their tapes were evaluated by an independent body of judges. ${ }^{28}$ Students exposed to the highly structured examination tended to perform more complete exams on the taped analysis. ${ }^{28}$

Each teacher who taught in the abdominal examination was required to attend a 1-hour evening session to observe one of the course directors (HS or DH) examine a real patient, be reminded of the proper sequence of inspection, auscultation, percussion and palpation, receive an extensive packet of teaching materials about the abdominal examination, ${ }^{21-26}$ and review objectives for the session as well as the exact logistics so that the session would run smoothly. In addition, particular stress was placed on modeling effective, kind, and sensitive communication skills for the benefit of both the students and volunteer patients. ${ }^{29}$

Of interest, our data show that rank and specialty were not significant contributing factors to overall evaluations of the session. Young and old, specialty and non-specialty teachers did well with preparation. As has been reported previously, we also had a fourth-year medical student who did well teaching second-year students the physical examination. ${ }^{30}$

Does teaching the abdominal examination well matter? Our data do not answer this question. What does the medical literature say? Important medical errors have been blamed on inadequate or incorrect physical examinations. ${ }^{31,32}$ Residency directors and others have noted significant variability in the physical examination skills of medical students, residents, and attending physicians. ${ }^{1-8}$

The strengths of our study are the large number of student evaluations $(\mathrm{N}=400)$, relatively small standard deviation, spontaneous student comments, and the significant number of patients and faculty who taught repeatedly.

The weakness of our study is the lack of outcome data on how these students performed on the abdominal examination compared to the other organ systems as third-year clerks and/ or as residents or attending physicians.

\section{Conclusion}

Volunteer patients, small group size, repetition, and faculty training all contributed to the abdominal examination's top ranking by anonymous student evaluations at our medical school over a 5-year period. We encourage other medical schools and hospitals that are charged with teaching the abdominal examination to recruit real clinic outpatients, use small group size, repetition, and mandatory faculty development sessions.

\section{Acknowledgments}

We are grateful to Peter Kelsey, MD, Paul O'Farrell, MBBS, Paola Blanco, MD, Steven Kappler, MD, Paul Sepe, MD, Tyler Berzin, MD, M.S., Suma Magge, MD, Gyanprakash Ketwaroo, MD, M.S., Molly Perencevich, MD, Edward Barnes, MD, M.P.H., Lawrence Borges, MD, M.P.H., and Walter Kim, MD, Ph.D. for their leadership in recruiting faculty, fellows, and residents each year to join us as teachers of the abdominal examination. We owe a great debt of gratitude to Francisca Xavier-Depina, BA, who recruits patients each year through reminder phone calls, surface mail, and email "save the date" messages. We are deeply grateful to each volunteer patient who joined us as co-teacher for the abdominal examination from 2008-2012. An abstract of this 
work was presented at Digestive Disease Week (DDW) 2014 in the American Gastroenterological Association's Clinical Practice Poster Session in Chicago, Illinois. This abstract received a Poster of Distinction Award from the American Gastroenterological Association.

Dr Shields is Professor of Medicine, Division of Gastroenterology, Hepatology and Endoscopy at Brigham and Women's Hospital, Harvard Medical School and Director of the Introduction to the Abdominal Examination for secondyear medical and dental students from 2007 to the present. At the time of this project, she was faculty member in the Division of Gastroenterology at Beth Israel Deaconess Medical Center. Dr Shields moved from Beth Israel Deaconess Medical Center to Brigham and Women's Hospital in January 2013.

Dr Fernandez-Becker is Assistant Clinical Professor of Medicine, Department of Medicine, Stanford University School of Medicine, Stanford, CA, USA. At the time this project began, she was a fellow in the Division of Gastroenterology at Beth Israel Deaconess Medical Center.

Dr Flier is Instructor in Medicine, Division of Gastroenterology, Beth Israel Deaconess Medical Center, and Harvard Medical School and faculty member for the Abdominal Examination.

Dr Vaughn is Assistant Professor of Medicine, Division of Gastroenterology, University of Minnesota Medical Center. At the time of this project, he was a resident in Internal Medicine at Beth Israel Deaconess Medical Center and then a fellow in the Division of Gastroenterology at Beth Israel Deaconess Medical Center.

Dr Tukey is a Pulmonary and Critical Care physician at Kaiser Permanente, Oakland, California. At the time this project was started, she was a resident in Internal Medicine at Beth Israel Deaconess Medical Center.

Dr Pelletier is Senior Project Manager for Harvard Medical School's Center for Evaluation. He has been the statistician for this project from 2007 to the present.

Dr Horst is Assistant Professor of Medicine in the Division of Gastroenterology at Beth Israel Deaconess Medical Center and Co-Director of the Abdominal Examination from 2007 to the present.

\section{Author contributions}

All authors contributed toward data analysis, drafting and critically revising the paper and agree to be accountable for all aspects of the work.

\section{Disclosure}

The authors report no conflicts of interest in this work.

\section{References}

1. Sacdeva AK, Loiacono LA, Amiel GE, Blair PG, Friedman M, Roslyn JJ. Variability in the clinical skills of residents entering training programs in surgery. Surgery. 1995;118(2):300-309.

2. Smith MA, Gertler T, Freeman K. Medical students' perceptions of their housestaffs' ability to teach physical examination skills. Acad Med. 2003;78(1):80-83.

3. Ortiz-Neu C, Walters CA, Tenebaum J, Colliver JA, Schmidt HJ. Error patterns of $3^{\text {rd }}$-year medical students on the cardiovascular physical examination. Teach Learn Med. 2001;13(3):161-166.

4. Windish DM, Paulman PM, Goroll AH, Bass EB. Do clerkship directors think medical students are prepared for the clerkship years? Acad Med. 2004;79(1):56-61.

5. Ramani S, Ring BN, Lowe R, Hunter D. A pilot study assessing knowledge of clinical signs and physical examination skills in incoming medicine residents. J Grad Med Educ. 2010;2(2):232-235.

6. Haring CM, van der Meer JW, Postma CT. A core physical examination in internal medicine: What should students do and how about their supervisors? Med Teach. 2013;35(9):e1472-e1477.

7. Haring CM, Cools BM, van der Meer, JW, Postma CT. Student performance of the general physical examination in internal medicine: an observational study. BMC Med Educ. 2014;14:73.

8. Hirschtick RE. The quick physical exam. JAMA. 2016;316(13):1363-1364.

9. Corbett EC Jr, Elnicki DM, Conaway MR. When should students learn essential physical examination skills? Views of Internal Medicine Clerkship Directors in North America. Acad Med. 2008;83(1):96-99.

10. Dull P, Haines DJ. Methods for teaching physical examination skills to medical students. Fam Med. 2003;35(5):343-348.

11. Smith MA, Burton WB, Mackay M. Development, impact and measurement of enhanced physical diagnosis skills. Adv Health Sci Educ Theory Pract. 2009;14(4):547-556.

12. Drazen JM, Shields HM, Loscalzo J. A division of medical communications in an academic medical center's department of medicine. Acad Med. 2014;89(12):1623-1629.

13. Junger J, Schäfer S, Roth C, Schellberg D, Friedman Ben-David M, Nikendei C. Effects of basic clinical skills training on objective structured clinical examination performance. Med Educ. 2005;39(10):1015-1020.

14. Schwind AJ, Boehler ML, Folse R, Dunnington G, Markwell SJ. Development of physical examination skills in a third-year surgical clerkship. Am J Surg. 2001;181(4):338-340.

15. Fletcher KE, Stern DT, White C, Gruppen LD, Oh MS, Cimmino VM. The physical examination of patients with abdominal pain: the long-term effect of adding standardized patients and small group feedback to a lecture presentation. Teach Learn Med. 2004;16(2):171-174.

16. Abe K, Suzuki T, Fujisaki K, Ban N. A national survey to explore the willingness of Japanese standardized patients to participate in teaching physical examination skills to undergraduate medical students. Teach Learn Med. 2009;21(3):240-247.

17. Barley BE, Fisher J, Dwinnell B, White K. Teaching foundational physical examination skills: study results comparing lay teaching associates and physician instructors. Acad Med. 2006;81(10 Suppl):S95-S97.

18. Mahaboob S, Lim LK, Ng CL, Ho QY, Leow ME, Lim EC. Developing the "NUS Tummy Dummy", a low-cost simulator to teach medical students to perform the abdominal examination. Ann Acad Med Singapore. 2010;39(2):150-151.

19. Jerg A, Ochsner W, Wander H, Traue HC, Jerg-Bretzke L. The FAMULATOR PLUS as an innovative approach for teaching physical examination skills. GMS J Med Educ. 2016;33(1):Doc4.

20. Butter J, Grant TH, Egan M, Kaye M, Wayne DB, Carrión-Carire V, McGaghie WC. Does ultrasound training boost Year 1 medical student competence and confidence when learning abdominal examination? Med Educ. 2007;41(9):843-848.

21. Bates B. A guide to physical examination and history taking. 4th Edition. Philadelphia: JB Lippincott Co.; 1987.

22. DeGowin R. DeGowin and DeGowin's bedside diagnostic examination, 5th Edition. New York: MacMillan Publishing Co.; 1987. 
23. Macleod J, Munro J. Clinical examination: A textbook for student and doctors by teachers of the Edinburgh Medical School, 7th Edition. New York: Churchill Livingston; 1986.

24. Prior JA, Silberstein JS, Stang JM. Physical diagnosis: The history and examination of the patient, 6th Edition. St. Louis: The CV Mosby Co.; 1981.

25. Schwartz MH. Textbook of physical diagnosis: History and examination, 2nd Edition. Philadelphia: WB Saunders Co.; 1994.

26. Greenberger NJ, Hinthorn DR. The Abdomen. In: History Taking and Physical Examination: Essentials and Correlates. St. Louis, Mosby Year Book; 1992:199-261.

27. Chang EH, Power DV. Are medical students comfortable with practicing physical examinations on each other? Acad Med. 2000;75(4):384-389.
28. Stillman PL, May JR, Meyer DM, Rutala PJ, Veach TL, Montgomery AB. A collaborative effort to study methods of teaching physical examination skills. J Med Educ. 1981;56(4):301-306.

29. Martens MJ, Duvivier RJ, van Dalen J, Verwijnen GM, Scherpbier AJ, van der Vleuten CP. Student views on the effective teaching of physical examination skills: a qualitative study. Med Educ. 2009;43(2):184-191.

30. Haist SA, Wilson JF, Brigham NL, Fosson SE, Blue AV. Comparing fourth-year medical students with faculty in the teaching of physical examination skills to first-year students. Acad Med. 1998;73(2):198-200.

31. Weiner S, Nathanson M. Physical examination. Frequently observed errors. JAMA. 1976;236(7):852-855.

32. Wray NP, Friedland JA. Detection and correction of house staff error in physical diagnosis. JAMA. 1983;249(8):1035-1037.
Advances in Medical Education and Practice

\section{Publish your work in this journal}

Advances in Medical Education and Practice is an international, peerreviewed, open access journal that aims to present and publish research on Medical Education covering medical, dental, nursing and allied health care professional education. The journal covers undergraduate education, postgraduate training and continuing medical education

\section{Dovepress}

including emerging trends and innovative models linking education, research, and health care services. The manuscript management system is completely online and includes a very quick and fair peer-review system. Visit http://www.dovepress.com/testimonials.php to read real quotes from published authors.

Submit your manuscript here: http://www.dovepress.com/advances-in-medical-education-and-practice-journal 